\title{
CARACTERIZAÇÃo E PROCESSAMENTO DE LEITE BUBALINO EM PÓ EM SECADOR POR NEBULIZAÇÃO
}

\author{
Roberta B. GUERRA, Elisa C. A. NEVES², Rosinelson S. PENA
}

\section{RESUMO}

Avaliou-se o processo de secagem por nebulização em "spray dryer" para a obtenção de leite bubalino em pó. Foram realizadas análises fisico-químicas no leite in natura e no leite desidratado, para averiguar perdas de macronutrientes ocorridas durante a secagem; análises microbiológicas para assegurar a qualidade higiênico-sanitária do processo e produto e análises sensoriais para estabelecer a aceitabilidade do produto. Foram obtidas isotermas de adsorção e dessorção de umidade a $25^{\circ} \mathrm{C}$, para o produto em pó, visando observar o seu comportamento higroscópico. O leite bubalino em pó obtido apresentou como características físicoquímicas: $3,4 \%$ de umidade, $23,2 \%$ de proteínas, $46,1 \%$ de gordura, $4,2 \%$ de cinzas, $0,5 \%$ de lecitina de soja e $22,6 \%$ de carboidratos totais. De acordo com os exames microbiológicos está apto para o consumo humano. O produto foi caracterizado como integral por não ter sofrido qualquer padronização. As perdas ocorridas para a maioria dos macronutrientes durante o processamento, foram inferiores a $5 \%$ e apenas o teor de proteínas apresentou variação superior a $15 \%$, devido à desnaturação da caseína em temperatura superior a $80^{\circ} \mathrm{C}$. O produto apresentou isotermas de adsorção do tipo III, mesmo comportamento apresentado pelo leite bovino. Através da isoterma de dessorção determinou-se o valor de umidade equivalente à monocamada, obtendo-se o valor médio de $4,4 \mathrm{~g} \mathrm{H}_{2} \mathrm{O} / 100 \mathrm{~g}$ b.s., o que validou o processo utilizado. O comportamento de histerese apresentado pelo produto foi similar ao do leite em pó integral, sendo a sua aceitabilidade de $74 \%$, muito próxima a $80 \%$ obtido para um leite em pó integral comercial.

Palavras-chave: nebulização; leite em pó; búfalo; caracterização.

\section{SUMMARY}

CHARACTERIZATION AND PROCESSING OF POWDERED BUFFALO MILK BY SPRAY DRYER. This work aims to show the process development based on the spray dryer for the obtaining of powdered buffalo milk. For that, physiochemical analyses were made in the milk in natura and later in the powdered product, which was also submitted to microbiological analysis to be sure that it could be consumed by humans; and to sensorial analysis for obtaining information about the product's acceptance. Sorption isotherms for the powdered product were obtained at $25^{\circ} \mathrm{C}$ with the purpose of perceiving the hygroscopic behavior. The buffalo's powdered milk presented the following characteristics: 3,4 \% moisture content, 23,2\% proteins, 46,1\% fat, 4,2\% ash, $0,5 \%$ soybean lecithin and $22,6 \%$ of total carbohydrates. The product was characterized as whole powdered buffalo milk, because it didn't suffer any standardization. Nutrient losses, during the process, were less then $5 \%$, and just for proteins the variation was more than $15 \%$. It can be justified by the desnaturation of the casein due to high temperatures $\left(>80^{\circ} \mathrm{C}\right)$. The powdered product presented type III sorption isotherms and the same behavior was observed for the whole powdered milk. Through sorption isotherms, the moisture content value, referent to the monolayer, was on an average of $4,4 \mathrm{~g} \mathrm{H} \mathrm{H}_{2} / 100 \mathrm{~g}$ dry solids, which confirms the process efficiency. The hysteresis behavior presented by the powdered product was similar of the whole powdered milk. The product acceptance was of $74 \%$, close to the commercial powdered milk acceptance.

Keywords: spray dryer; powder milk; buffalo; characterization.

\section{1 - INTRODUÇÃO}

Encontra-se na região da Amazônia, concentrado principalmente na Ilha de Marajó, o maior efetivo de bubalinos do Brasil. Nos últimos anos tem aumentado o interesse na criação desses animais principalmente pelas vantagens que apresentam sobre os bovinos, em relação ao trabalho, à produção de carne e particularmente a de leite [9], que de acordo com BENEVIDES [2] é a produção mais importante do gado bubalino.

O leite bubalino apresenta características próprias permitindo a sua fácil identificação físico-química e organoléptica, residindo na sua qualidade a maior vantagem. Possui teores de proteínas, gorduras e minerais, que superam os do leite bovino, permitindo a complementação das necessidades alimentares de crianças e adultos.

Recebido para publicação em 17/11/2003. Aceito para publicação em 11/08/2005 (001250).

$D E Q A L / C T / U F P A$ - Campus Universitário do Guamá. Endereço: Rua Augusto Corrêa, 1, Guamá. CEP: 66075-900, Belém-PA, Brasil. E-mail:rspena@ufpa.br

* A quem a correspondência deve ser enviada.
Entretanto, é no seu aproveitamento industrial que reside, na prática, sua grande importância, por proporcionar a obtenção de produtos lácteos de boa qualidade, podendo-se destacar: queijos, doce de leite, manteiga e iogurte [2]. A industrialização do leite bubalino no Brasil é uma realidade. Pois, além do queijo Mussarela, diversos laticínios têm elaborado vários derivados a partir deste leite [1].

A secagem do leite para obtenção do produto em pó está configurada entre as diversas tecnologias para o seu aproveitamento. Neste tipo de processo, os nutrientes são conservados quase que completamente. Outras vantagens desta tecnologia é que o produto em pó possibilita um transporte mais econômico, planejamento de produção, distribuição e a fabricação de derivados diversos, podendo ser, portanto, uma via tecnológica viável, visto que o leite bubalino apresenta características organolépticas indesejáveis se consumido in natura [7].

Devido ao exposto, este trabalho teve como objetivo obter leite bubalino em pó integral, através de secagem por nebulização, em "spray dryer", dentro de padrões microbiológicos e características físico-químicas e sensoriais aceitáveis, bem como avaliar o seu comportamento higroscópico, por meio de isotermas de adsorção e des- 
sorção de umidade, possibilitando sugerir condições de secagem, de vida-de-prateleira e de armazenamento.

\section{2 - MATERIAL E MÉTODOS}

\section{1 - Matérias-primas}

Utilizou-se leite bubalino in natura, proveniente de uma fazenda localizada no município de Benevides (PA) e lecitina de soja marca Grings, adquirida no comércio local.

\section{2 - Metodologia}

\subsection{1 - Caracterização físico-química}

As análises foram realizadas no leite in natura, pasteurizado e em pó, de acordo com metodologias propostas pelo INSTITUTO ADOLFO LUTZ [13] e por SILVA et al. [17]. Foram determinados: acidez total titulável, por titulação com $\mathrm{NaOH} 0,1 \mathrm{~N} ; \mathrm{pH}$, em potenciômetro digital da marca PROCYON, modelo 310; teor de gordura, pelo método do butirômetro de Gerber; proteínas totais, pelo método Kjedahl, utilizando aparelho destilador de nitrogênio TECNAL, modelo TC036, e fator de conversão do nitrogênio para proteína foi 6,38 ; umidade, em estufa a $105^{\circ} \mathrm{C}$ e cinzas, por calcinação a $550^{\circ} \mathrm{C}$, em mufla QUIMIS, modelo Q-327.

\subsection{2 - Determinações microbiológicas}

Foram determinados para o leite in natura e pasteurizado: Salmonella sp. e Coliformes a $45^{\circ} \mathrm{C}$. Para o leite em pó foram determinados Salmonella sp., Coliformes a $45^{\circ} \mathrm{C}$ e Staphylococcos aureus, atendendo as recomendações do Ministério da Saúde [4] e de acordo com metodologias propostas por VANDERZANT \& SPLITSTOESSER [18].

\subsection{3 - Produção do leite em pó}

O leite in natura foi inicialmente submetido à filtração, para eliminação de sujidades, e a pasteurização foi do tipo lenta a $67^{\circ} \mathrm{C}$ por $30 \mathrm{~min}$., seguida de resfriamento até $30^{\circ} \mathrm{C}$. Em seguida, o leite foi novamente filtrado (malha de $0,5 \mathrm{~mm}$ ), para evitar o entupimento do bico injetor do secador. O leite foi submetido à secagem por nebulização, em um "spray dryer" semi-industrial, marca NIRO ATOMIZER, com temperatura do ar na entrada e saída do secador de $140^{\circ} \mathrm{C}$ e $75^{\circ} \mathrm{C}$, respectivamente. A temperatura do ar na entrada do secador foi estabelecida com base na literatura [19]. Esta deve ser tal, que o fluxo de ar não permita que o produto atinja niveis de concentração, que possibilitem explosão no secador. Segundo estes autores a autoignição do leite em pó integral pode ocorrer a partir de $144^{\circ} \mathrm{C}$. A temperatura do ar na saída foi estabelecida visando minimizar, ao máximo, a desnaturação da caseina do leite $\left(<80^{\circ} \mathrm{C}\right)$.

\subsection{4 - Análise sensorial}

O leite bubalino em pó elaborado, juntamente com um produto comercial (leite bovino em pó integral), foram submetidos à avaliação sensorial, utilizando-se o Teste de Aceitação com escala de 9 pontos, ancorados nos extremos por: gostei muitíssimo (9) e desgostei muitíssimo (1). O produto comercial foi utilizado para efeitos de comparação. Foram utilizados 30 provadores, não treinados, de ambos os sexos, com idade de 20 e 60 anos. Amostras dos produtos, após reconstituição em água a $60^{\circ} \mathrm{C}$, para restabelecimento das concentrações de sólidos dos respectivos leites in natura, foram servidas aos provadores, ao acaso e a uma temperatura de aproximadamente $40^{\circ} \mathrm{C}$. Para calcular a aceitação utilizou-se a equação 1.

$A=\frac{(M \times 100)}{9}$

onde : A é a aceitação; $\mathrm{M}$ a média das notas obtidas e 9 a nota máxima.

\subsection{5 - Obtenção de isotermas de sorção}

Foram construídas isotermas de adsorção e dessorção de umidade a $25^{\circ} \mathrm{C}$. Na obtenção dos dados de equilíbrio de adsorção, amostras do produto, com massas de aproximadamente $1 \mathrm{~g}( \pm 2 \mu \mathrm{g})$, foram submetidas à desidratação em dessecador com sílica-gel, sob vácuo, para evitar escurecimento do produto devido à reação de Maillard. Após 24 horas, as amostras foram dispostas em dessecador contendo água. Para obtenção dos dados de equilíbrio de dessorção, as amostras do produto, após o processo de adsorção, foram submetidas a umidificação, em dessecador contendo água na base, na temperatura de trabalho $\left(25^{\circ} \mathrm{C}\right)$, por 24 horas, sendo, em seguida, transferidas para um dessecador contendo sílica-gel. Nos dois casos o conjunto foi mantido em estufa a $25^{\circ} \mathrm{C} \pm 1^{\circ} \mathrm{C}$, de onde foram retiradas amostras, em duplicata e em tempos crescentes, para determinação da umidade, por diferença de peso (pesagem), e da atividade de água, em higrômetro AQUALAB 3TE da Decagon. Durante os processos de adsorção e dessorção as amostras do produto foram submetidas a acompanhamento, para identificar quaisquer alterações visualmente perceptiveis, como: "caking", escurecimento, grau de coesão e crescimento de fungos.

\subsection{6 - Determinação da monocamada}

A monocamada foi determinada utilizando a forma linearizada da equação 2, proposta por BRUNAUER, EMMET \& TELLER [5], para a região linear das isotermas.

$$
\frac{a_{w}}{\left(1-a_{w}\right) \cdot m}=\frac{1}{m_{o} \cdot C}+\frac{(C-1)}{m_{o} \cdot C} \cdot a_{w}
$$

onde: $\mathrm{m}$ é a umidade; a a atividade de água; $\mathrm{m}$ a monocamada e $\mathrm{C}$ constante relacionada com o calor de adsorção.

\subsection{7 - Predição das isotermas}

Testou-se a aplicabilidade do modelo matemático 
proposto por Guggenheim-Anderson-De Boer (GAB) [15] (equação 3) na predição dos dados de equilíbrio de sorção do produto. Os ajustes foram feitos através de regressão não linear, com auxílio do aplicativo STATISTICA for Windows 5.1B.

$$
\frac{m}{m_{o}}=\frac{c \cdot k \cdot a_{w}}{\left[\left(1-k \cdot a_{w}\right)\left(1-k \cdot a_{w}+c \cdot k \cdot a_{w}\right)\right]}
$$

onde: $\mathrm{m}$ é umidade; a atividade de água; $\mathrm{m}_{\text {。 }}$ monocamada; c constante de Guggenheim e k fator relacionado as multicamadas.

\subsection{8 - Análise estatística dos resultados}

O desvio padrão relativo - DPR(\%) (equação 4) foi calculado, para obter informações sobre variações na composição do leite, devido aos tratamentos sofridos (processamento). Para efeitos de avaliação considerou-se que dois ou mais parâmetros se apresentaram dentro de uma faixa aceitável, se o DPR(\%) foi inferior a $10 \%$, de acordo com limites recomendados por GOMES [8], para produtos agropecuários.

$$
\operatorname{DPR}(\%)=\frac{s}{M} \cdot 100
$$

onde: s é o desvio padrão e M a média aritmética dos valores observados.

\section{3 - RESULTADOS E DISCUSSÃo}

\section{1 - Avaliação do processo de obtenção do leite bubalino em pó}

Para se chegar as melhores condições de secagem para o leite bubalino, em relação à umidade final do produto e ao escurecimento, foram realizados diferentes ensaios. As melhores condições de secagem foram obtidas com as temperaturas do ar na entrada e saída do secador de $140^{\circ} \mathrm{C}$ e $75^{\circ} \mathrm{C}$, respectivamente. Nestas condições o produto final apresentou umidade de 3,4\%, inferior aos $3,5 \%$ exigidos para leite em pó, e não sofreu escurecimento característico da reação de Maillard. O produto obtido foi caracterizado como integral por não ter sido submetido a nenhuma operação de padronização, mantendo as características do leite in natura.

Os resultados da caracterização físico-química do leite bubalino nas diferentes etapas do processamento são apresentados na Tabela 1. A composição determinada para o leite bubalino in natura utilizado está de acordo com HUHN et al. [10]. O produto apresentou na sua composição centesimal $3,4 \%$ de umidade, $23,2 \%$ de proteínas, $46,1 \%$ de gordura, $4,2 \%$ de cinzas, $0,5 \%$ de lecitina de soja e $22,6 \%$ de carboidratos totais.

O DPR para a maioria dos macronutrientes, durante o processamento, foi inferior a $10 \%$, estando dentro da faixa de variação estabelecida como aceitável. Apenas os teores de acidez e proteína apresentaram DPR ligeiramente superiores a $10 \%$, indicando desnaturação de caseína em temperatura superior a $80^{\circ} \mathrm{C}$ durante, principalmen-
TABELA 1 - Caracterização físico-química do leite bubalino

\begin{tabular}{lcccc}
\hline \multicolumn{1}{c}{ Propriedade } & $\begin{array}{c}\text { Leite } \\
\text { bubalino } \\
\text { “n natura }\end{array}$ & $\begin{array}{c}\text { Leite } \\
\text { bubalino } \\
\text { pasteurizado }\end{array}$ & $\begin{array}{c}\text { Leite } \\
\text { bubalino } \\
\text { em pó }\end{array}$ & $\begin{array}{c}\text { DPR } \\
(\%)\end{array}$ \\
\hline $\mathrm{pH}\left(30^{\circ} \mathrm{C}\right)$ & 6,8 & - & - & - \\
Acidez (\% b.s.) & 1,0 & 1,0 & 0,8 & 12,4 \\
Gordura (\% b.s.) & 43,7 & 44,7 & 47,7 & 4,6 \\
Cinzas (\% b.s.) & 4,0 & 4,0 & 4,4 & 5,6 \\
Proteinas (Nx6,38) (\% b.s.) & 31,0 & 29,0 & 24,0 & 12,9 \\
Carboidratos totais (\% b.s.) & 21,3 & 22,3 & 23,9 & 5,9 \\
\hline "Média de duas determinações (erros relativos inferiores a 10\%); \% b.s. = g por 100g do \\
material seco.
\end{tabular}

te, a etapa de secagem. A desnaturação da caseína favoreceu a sua colmatagem nas superficies internas do secador.

Devido à desnaturação da caseína (emulsificante natural do leite) e ao teor de gordura do leite bubalino, aproximadamente duas o do leite bovino, houve problema com a sua reconstituição. Isso foi selecionado com a adição de $0,5 \%$ de lecitina de soja (emulsificante) em relação à massa final do produto. O valor de $0,5 \%$ de lecitina de soja foi utilizado com base no valor máximo permitido pela legislação [4], para o leite em pó instantâneo. Apesar de não existir permissividade na legislação para a adição de lecitina de soja em leite em pó integral, o leite bubalino é um caso particular, devido ao elevado teor de gordura, o que dificulta a sua reconstituição.

Os resultados das análises microbiológicas realizadas no leite bubalino pasteurizado e em pó são apresentados na Tabela 2, os quais estão de acordo com padrões estabelecidos na legislação brasileira [4], atestando a qualidade higiênico-sanitária do produto e que os processamentos utilizados (pasteurização e secagem) foram satisfatórios, estando o produto apto para consumo humano. Na Figura 1 estão ilustrados os resultados obtidos nos testes de aceitação aplicados ao leite bubalino em pó integral e ao leite em pó integral comercial.

\begin{tabular}{|c|c|c|c|}
\hline $\begin{array}{l}\text { Parâmetro } \\
\text { analisado* }\end{array}$ & $\begin{array}{l}\text { Leite bubalino } \\
\text { pasteurizado }\end{array}$ & $\begin{array}{l}\text { Leite bubalino } \\
\text { em pó }\end{array}$ & Padrões \\
\hline Salmonella sp. (em 25g) & Ausência & Ausência & Ausência \\
\hline Coliformes a $45^{\circ} \mathrm{C}$ & $<3 \mathrm{NMP} / \mathrm{mL}$ & $<3 \mathrm{NMP} / \mathrm{g}$ & $\begin{array}{c}1 \times 10^{1} \mathrm{NMP} / \mathrm{g} \\
(\mathrm{mL})\end{array}$ \\
\hline Staphilacoccus aureus & - & $<1 \times 10^{1} \mathrm{NMP} / \mathrm{g}$ & $1 \times 10^{2} \mathrm{NMP} / \mathrm{g}$ \\
\hline
\end{tabular}

TABELA 2 - Avaliação microbiológica do leite bubalino

De acordo com os testes de aceitação, o leite bubalino em pó, obteve aceitação de $74 \%$, enquanto o leite em pó integral comercial utilizado, para efeitos de comparação, obteve $80 \%$, evidenciando a boa aceitabilidade do produto elaborado. Entre os comentários feitos por alguns provadores que atribuíram conceitos inferiores a indiferente, para o leite bubalino em pó, merece destaque a rejeição do produto, devido seu sabor, odor e aroma pronunciados.

\section{2 - Avaliação higroscópica do leite bubalino em pó}

Os dados de equilíbrio de adsorção e dessorção de umidade para o leite bubalino em pó a $25^{\circ} \mathrm{C}$, são apresentados na Tabela 3 e Figura 2. É importante ressaltar 


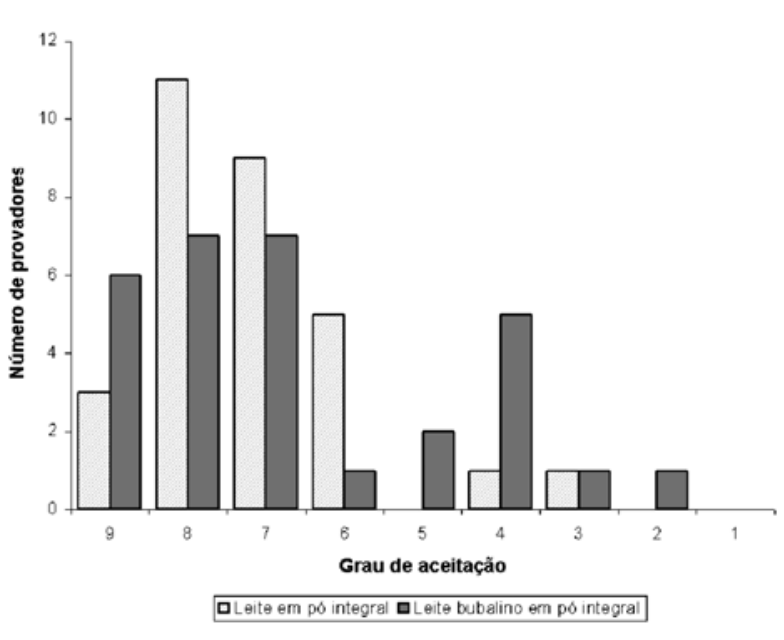

FIGURA 1 - Resultados obtidos no teste de aceitação dos leites em pó integrais

que durante a obtenção dos dados de equilíbrio de adsorção e dessorção de umidade, através de inspeção visual, não foram observadas alterações nas características do produto, seja na mudança de cor, seja de aglomeração (perda de fluidez). Do ponto de vista prático significa que esta não é uma variável que possa ser utilizada para identificar se o produto sofreu umidificação, por exemplo, devido ao armazenamento não adequado.

Observa-se que as isotermas de adsorção e dessorção apresentam concavidade para o eixo das abscissas até niveis intermediários de $\mathrm{a}_{*}$, assumindo uma forma exponencial em a superior a 0,7 , que as classifica, segundo SALWIN [16], como isotermas do tipo III. Embora o leite bubalino em pó integral apresente peculiaridades em relação à sua composição química, suas isotermas apresentam o mesmo comportamento observado por BERLIN, ANDERSON \& PALLANSCH [3] e IGLESIAS \& CHIRIFE [11], para leite em pó integral.

Na Figura 2 pode-se observar o efeito de histerese para o produto, o qual inicia em niveis de a de aproximadamente 0,85 e cobre toda a faixa de a inferior estudada. Segundo LABUZA [14] o efeito de histerese é característico da região de condensação capilar, podendo se estender até a região de multicamadas e, muito raramente, até a monocamada. Desta forma, o comportamento de histerese do leite bubalino em pó se enquadra em um caso raro. Porém, comportamento semelhante foi observado por BERLIN, ANDERSON \& PALLANSCH [3] e IGLESIAS \& CHIRIFE [11], para o leite em pó.

As umidades equivalentes à monocamada para os processos de adsorção e dessorção, determinadas através da equação de $\mathrm{BET}$, foram de $3,1 \mathrm{~g} \mathrm{H}_{2} \mathrm{O} / 100 \mathrm{~g}$ b.s. e 4,4g $\mathrm{H}_{2} \mathrm{O} / 100 \mathrm{~g}$ b.s., respectivamente. Estes valores dão respaldo ao processo de secagem utilizado e estão de acordo com os encontrados por SALWIN [16], IGLESIAS \& CHIRIFE [12] e CABRAL \& ALVIM [6], para leite em pó in-
TABELA 3 - Dados de adsorção e dessorção para o leite bubalino em pó a $25^{\circ} \mathrm{C}$

\begin{tabular}{cccc}
\hline \multicolumn{2}{c}{ Adsorção } & \multicolumn{2}{c}{ Dessorção } \\
\hline $\mathrm{a}_{\mathrm{w}}$ & $\mathrm{m}\left(\mathrm{g} \mathrm{H}_{2} \mathrm{O} / 100 \mathrm{~g} \mathrm{~b} . \mathbf{s} \text {. }\right)^{\star}$ & $\mathrm{a}_{\mathrm{w}}$ & $\mathrm{m}\left(\mathrm{g} \mathrm{H}_{2} \mathrm{O} / 100 \mathrm{~g} \mathrm{~b} . \mathbf{s} .\right)^{*}$ \\
\hline 0,05 & 2,14 & 0,96 & 37,37 \\
0,10 & 2,86 & 0,88 & 20,07 \\
0,22 & 3,83 & 0,82 & 15,59 \\
0,36 & 4,73 & 0,78 & 13,68 \\
0,45 & 5,37 & 0,68 & 10,67 \\
0,52 & 5,75 & 0,64 & 10,38 \\
0,60 & 6,26 & 0,55 & 8,70 \\
0,63 & 6,67 & 0,50 & 8,06 \\
0,67 & 7,19 & 0,45 & 7,28 \\
0,73 & 8,32 & 0,36 & 6,38 \\
0,76 & 9,39 & 0,30 & 6,29 \\
0,84 & 15,15 & 0,26 & 6,05 \\
0,86 & 17,72 & 0,23 & 5,74 \\
0,90 & 21,92 & 0,10 & 3,88 \\
0,96 & 37,35 & \multicolumn{2}{c}{} \\
\hline Média de duas determinaçóes (erros relativos inferiores a 10\%).
\end{tabular}

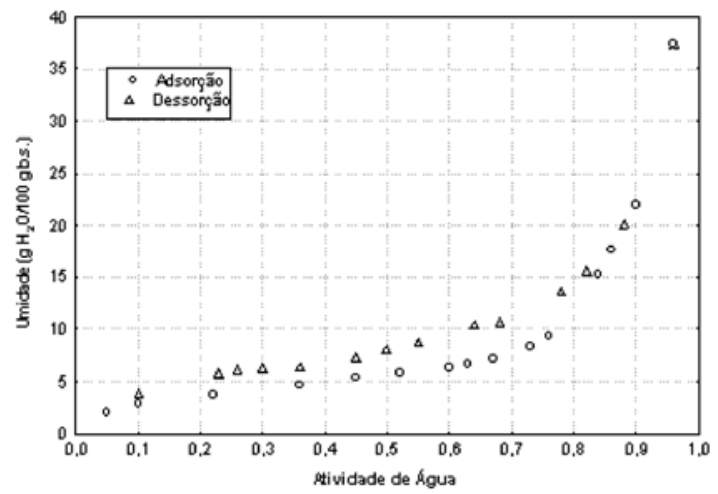

FIGURA 2 - Isotermas de adsorção e dessorção para o leite bubalino em pó a $25^{\circ} \mathrm{C}$

tegral. Vale ressaltar que, de acordo com os dados de equilíbrio de adsorção, o produto obtido terá estabilidade microbiológica assegurada $\left(a_{*}<0,6\right)$ se apresentar umidades inferiores a 6,3 $\mathrm{g} \mathrm{H}_{2} \mathrm{O} / 100 \mathrm{~g}$ b.s.

\section{3 - Aplicação de GAB na predição dos dados de equilibrio}

Os parâmetros do ajuste do modelo de GAB aos dados de equilíbrio de adsorção e dessorção são apresentados na Tabela 4. O coeficiente de determinação ( $\mathrm{r}^{2}$ ) e o desvio médio relativo $(\mathrm{P})$ revelam os bons ajustes do modelo, indicando que o mesmo pode ser utilizado na predição de dados de equilíbrio de adsorção e dessorção para o leite bubalino em pó.

TABELA 4 - Parâmetros do ajuste do modelo de GAB

\begin{tabular}{cccccc}
\hline & \multicolumn{5}{c}{ Parâmetros } \\
\cline { 2 - 6 } Isoterma & $\mathrm{m}_{\mathrm{o}}$ & $\mathrm{c}$ & $\mathrm{k}$ & $\mathrm{r}^{2}$ & $\mathrm{P}(\%)$ \\
\hline Adsorção & 2,9 & 37,3 & 0,96 & 0,9946 & 8,4 \\
Dessorção & 4,0 & 57,9 & 0,93 & 0,9896 & 8,9 \\
\hline
\end{tabular}

\section{4 - CONCLUSÕES}

Obteve-se um produto aceitável dentro de padrões microbiológicos, físico-químicos e sensoriais. 
As perdas de nutrientes ocorridas durante o processamento do leite bubalino em pó não depreciaram significativamente a sua qualidade, validando os parâmetros de processo utilizados.

Durante a obtenção dos dados de equilíbrio de adsorção e dessorção de umidade não foram observadas alterações nas características do produto, como mudança de cor e perda de fluidez.

O comportamento das isotermas de adsorção e dessorção de umidade, e do efeito de histerese, para o leite bubalino em pó, foi equivalente ao encontrado na literatura, para leite em pó.

O valor da umidade equivalente a monocamada, determinado para o processo de dessorção, respaldou o processo de secagem utilizado, visto que o dispêndio de energia poderia ser muito grande, para secar o produto abaixo da monocamada.

\section{5 - REFERENCIAS BIBLIOGRÁFICAS}

[1] BCB. Associação Brasileira de Criadores de Búfalo. Textos sobre leite de búfala. Disponivel em: <http:/ / www.bufalo.com.br>. Acesso em 15 jul. 2003.

[2] BENEVIDES, C.M. Leite de búfala: qualidades tecnológ i c a s. D i s p o n íve 1 e $\mathrm{m}$ : <http://www.bichoonline.com.br/artigos/ha0015.htm >. Acesso em 23 set. 2002.

[3] BERLIN, E; ANDERSON, B.A; PALLANSCH, M.J. Effect of temperature on water vapor sorption by dried milk powders. Journal of Food Science, v.53, n.2, p.146-149, 1970.

[4] BRASIL. Agência Nacional de Vigilância Sanitária. Resolução RDC n ${ }^{\circ} 12$, de 02 de janeiro de 2001. Regulamento Técnico sobre padrões microbiológicos para alimentos. Diário Oficial [da República Federativa do Brasil], Brasília 10 jan. 2001.

[5] BRUNAUER, S.; EMMET, P.H.; TELLER, E. Adsorption of gases in multimolecular layers. Journal American Chemical Society, v.60, p.309-319, 1938.

[6] CABRAL, A.C.D; ALVIM, D.D. Alimentos desidratados. Conceitos básicos para sua embalagem e conservação. Boletim do Instituto de Tecnologia de Alimentos, v.18, n.1, p.1-68, 1981.
[7] CARVALHO, O. Alimento desidratado: particularidades. Alimentos e Bebidas, v.4, n.5, p.30-31, 1968.

[8] GOMES, F.P. Estatística moderna da pesquisa agropecuária. Piracicaba: Potafos, 1984. 160p.

[9] HÜHN, S.; LOURENÇO Jr., J.B.; MOURA CARVALHO, L.O.D.; NASCIMENTO, C.N.B. Caracteristicas, peculiaridade e tecnologia do leite de búfala. Belém: EMBRAPA-CPATU, 1991.51p.

[10] HÜHN, S.; GUIMARÃES, M.C.F.; NASCIMENTO, C.N.B.; MOURA CARVALHO, L.O.D.; MOREIRA, E.D.; LOURENÇO Jr., J.B. Estudo comparativo da composição química do leite de zebuínos e bubalinos. Boletim de Pesquisa, n.36, p.5-14, 1982.

[11] IGLESIAS, H.A; CHIRIFE, J. Handbook of food isotherms: Water sorption parameters for food and food components. London: Academic Press, 1982.347p.

[12] IGLESIAS, H.A; CHIRIFE, J. Prediction of the effect of temperature on water sorption isotherms of food material. Lebensmittel Wissenschaft and Tecnologie, v.11, p.109-116, 1976.

[13] INSTITUTO ADOLFO LUTZ. Normas analiticas do Instituto Adolf Lutz: Métodos químicos e físicos para a análise de alimentos. 3.ed. São Paulo, 1985. 533p.

[14] LABUZA, T.P. Sorption phenomena in foods. Food Technology, v.22, n.3, p.15-24, 1968.

[15] MAROULIS, Z.B.; TSAMI, E.; ARINOS-KOURIS, D.; SARAVACOS, G.D. Application of the GAB model to the sorption isotherms for dried fruits. Journal of Food Engeneering, 1988.

[16] SALWIN, H. Defining minimum moisture contents for dehydrated foods. Food Technology, v.13, p.594-585, 1959.

[17] SILVA, P.H.F; PEREIRA, D.B.C.; OLIVEIRA, L.L.; COSTA Jr., L.C.G. Físico-química do Leite e derivados: métodos analíticos. Juiz de Fora, 1997, 190p.

[18] VANDERZANT, C., SPlitTstoesser, D.F. Compendium of methods for microbiological examination of foods. 3.ed., Washington: American Public Health, 1992.914p.

[19] VARNAN, A; SUTHERLAND, J.P. Leche y Productos Lácteos. Zaragoza: Acribia, 1995. 476p. 